\title{
Results of endovascular treatment of iliac and femoral symptomatic lesions. Identification of re-intervention risk factors
}

\author{
Wojciech Stecko', Wojciech Rogala ${ }^{2}$, Marcin Feldo ${ }^{2}$, Marek Ilzecki ${ }^{2}$, \\ Waclaw Karakula ${ }^{2}$, Aleksander Kasprzak ${ }^{3}$, Tomasz Zubilewicz ${ }^{2}$ \\ 'Department of Invasive Radiology, Independent Public Health Care Ministry of Internal Affairs, Rzeszow, Poland \\ ${ }^{2}$ Department of Vascular Surgery and Angiology, Medical University of Lublin, Poland \\ ${ }^{3}$ New York University, Class 2020 Biochemistry Pre-Med, USA, Buffalo, United States
}

\begin{abstract}
Introduction. The aim of the study was to assess a presence of peripheral arterial disease risk factors in patients with symptomatic femoral and iliac lesions treated with use of Jaguar and Supera nitinol stents and to estimate potential relation between these factors and reintervention rate.

Material and methods. The study group consisted of 60 patients between 46 and 85 years of age who presented with typical symptoms of intermittent claudication or critical limb ischemia and underwent percutaneous transluminal angioplasty with stenting. We examined and divided group into two subgroups - patients who experienced or did not experience need of reintervention in treated lesion.

Results. During the follow-up 24 (40\%) of patients underwent reintervention in treated artery due to recurrent symptoms of disease. Need of target lesion revascularization occurred more frequent in patients with hypertension $(O R=2.5)$, patient older than $68(O R=1.75)$ and smokers $(O R=1.75)$. Patency of all three arteries below knee protected from reintervention.

Conclusions. Jaguar and Supera self-expanding nitinol stents has several advantages and its use were characterized by high procedural success and moderate frequency of reintervention correlated to some clinical findings like hypertension. Further studies are necessary to estimate factors disturbing and interfering with long-term patency.
\end{abstract}

Key words: self-expanding nitinol stents, risk factors, revascularization

Acta Angiol 2017; 23, 3: II5-123

\section{Introduction}

Peripheral arterial disease (PAD) is the third leading cause of cardiovascular morbidity after myocardial infarction and stroke and is growing problem of developing as well as developed countries (Table I) [I].

Its main reason is atherosclerosis which once initiated evolves, accelerated by both numerous well known risk factors and also newly understood inflammatory mechanisms [2]. Increasing life expectancy and growing diabetes mellitus incidence rate causes that peripheral arterial disease or lower limb ischemia (LLI) is not only diagnosed more often in recent times but also influenced by diabetes mellitus may be associated with an increased mortality rate, which is shown in Figure I [3].

Apart from intensive risk factors modification, which is obligatory basis of therapy, pharmacologic interventions and supervised exercise programs in many cases early interventional treatment - surgical or endovascular - is necessary after diagnosis [4-6]. 
Table I. Estimated number of people living with peripheral artery disease in high-income countries, low-income and middle-income countries, and worldwide in the years 2000 and 2010, and the rate of change from 2000 to 2010 _ data from literature [I]

\begin{tabular}{|c|c|c|c|c|c|c|c|c|c|}
\hline & \multicolumn{3}{|c|}{$\begin{array}{l}\text { People living with peripheral } \\
\text { artery disease in year } 2000 \\
\text { (thousands) }\end{array}$} & \multicolumn{3}{|c|}{$\begin{array}{l}\text { People living with peripheral } \\
\text { artery disease in } 2010 \text { (thousands) }\end{array}$} & \multicolumn{3}{|c|}{$\begin{array}{l}\text { Rate of change } \\
(2000-2010)\end{array}$} \\
\hline & $\begin{array}{l}\text { High- } \\
\text {-income } \\
\text { countries }\end{array}$ & $\begin{array}{c}\text { Low-income } \\
\text { and middle- } \\
\text {-income } \\
\text { countries }\end{array}$ & Worldwide & $\begin{array}{l}\text { High- } \\
\text {-income } \\
\text { countries }\end{array}$ & \begin{tabular}{|l|} 
Low-income \\
and middle- \\
-income \\
countries
\end{tabular} & Worldwide & $\begin{array}{l}\text { High- } \\
\text {-income } \\
\text { countries }\end{array}$ & $\begin{array}{c}\text { Low-income } \\
\text { and middle- } \\
\text {-income } \\
\text { countries }\end{array}$ & Worldwide \\
\hline $25-29$ years & 2311 & 10756 & 13068 & 2381 & 12037 & 14419 & $3.02 \%$ & $11.91 \%$ & $10.34 \%$ \\
\hline 30-34 years & 2803 & 11469 & $14 \quad 272$ & 2760 & 12343 & $15 \quad 103$ & $-1.52 \%$ & $7 \cdot 62 \%$ & $5.82 \%$ \\
\hline $35-39$ years & 3486 & II 247 & 14733 & 3343 & 13776 & 17119 & $-4 \cdot 12 \%$ & $22 \cdot 49 \%$ & $16 \cdot 19 \%$ \\
\hline $40-44$ years & $407 I$ & $11 \quad 138$ & $15 \quad 209$ & 3938 & 14707 & 18645 & $-3 \cdot 28 \%$ & $32.05 \%$ & $22 \cdot 59 \%$ \\
\hline $45-49$ years & 4528 & 11408 & 15936 & 4851 & 14354 & 19205 & $7 \cdot 14 \%$ & $25 \cdot 83 \%$ & $20.51 \%$ \\
\hline $50-54$ years & 4907 & 9902 & 14808 & 5503 & 14100 & 19603 & $12 \cdot 15 \%$ & $42 \cdot 40 \%$ & $32 \cdot 37 \%$ \\
\hline $55-59$ years & 4530 & 9111 & $1364 \mid$ & 5948 & $14 \quad 170$ & 20118 & $31 \cdot 31 \%$ & $55 \cdot 53 \%$ & $47 \cdot 49 \%$ \\
\hline $60-64$ years & 5342 & 9074 & 14416 & 6242 & 11787 & 18029 & $16.85 \%$ & $29.90 \%$ & $25.06 \%$ \\
\hline $65-69$ years & 5287 & 8416 & 13704 & 5547 & $10 \quad 124$ & 15670 & $4.90 \%$ & $20 \cdot 29 \%$ & $14.35 \%$ \\
\hline 70-74 years & 5594 & 6953 & 12547 & 6043 & 9020 & 15063 & $8.02 \%$ & $29 \cdot 73 \%$ & $20.05 \%$ \\
\hline $75-79$ years & 4808 & 4960 & 9768 & 5370 & 7012 & 12382 & $11.68 \%$ & $41 \cdot 36 \%$ & $26.75 \%$ \\
\hline $80-84$ years & 3107 & 3015 & 6123 & 4723 & 4396 & 9118 & $51 \cdot 98 \%$ & $45 \cdot 77 \%$ & $48.92 \%$ \\
\hline $85-89$ years & 2246 & $|4| \mid$ & 3658 & 3028 & 2087 & 5115 & $34 \cdot 80 \%$ & $47 \cdot 86 \%$ & $39 \cdot 84 \%$ \\
\hline$\geq 90$ years & 1174 & 544 & 1717 & 1611 & 864 & 2474 & $37 \cdot 22 \%$ & $58.82 \%$ & $44.09 \%$ \\
\hline Total & $54 \quad 195$ & 109405 & 163600 & 61287 & 140775 & 202062 & $13.08 \%$ & $28.67 \%$ & $23.51 \%$ \\
\hline
\end{tabular}

In spite of advances in invasive treatment and significant improvement of optimal pharmacotherapy with statin mortality among patients hospitalized due to lower limb ischemia seems to remain unchanged [7-9].

Methods of endovascular treatment have evolved in last years from simple balloon angioplasty through balloon-expandable stents implantation to use of nitinol self-expanding stents. First generation of stents did not meet the expectations for better long term results compared to PTA alone. Self-expanding stents inspire hope of better long term results defined as permanent recovery from symptoms with lower reinterventions rate.

However, the significant prevalence of elective nitinol stent implantation strategy over PTA alone has not been proved and better outcomes after routine use of nitinol stents are controversial [10-14]. In spite of this fact a trend toward wide implantation of self-expanding nitinol stents is observed among operators performing superficial femoral artery (SFA) interventions.

The ideal stent for use in superficial femoral artery should combine attributes like flexibility allowing to use in cross-over technique, radial force and in popliteal region also significant bending- and compression resistance. Those criteria seems to be fulfilled by Jaguar (Balton) and Supera (Abott) stents (Fig. 2). First listed, Jaguar not only can be modified during intravascular deployment, but safely withdrawn and repositioned during the same medical procedure as well and thus enables precise positioning and deployment [15]. Supera with its interwoven nitinol design seems to be very compression- and movement-resistant which prevents fractures in distal parts of SFA and popliteal region.

The aim of our study was to assess the presence of peripheral arterial disease risk factors in patients with symptomatic femoral and iliac lesions treated with use of Jaguar and Supera nitinol stents, but also to estimate potential relation between these factors and reintervention rate. Additionally, we checked whether some significant differences between stents will appear and last, we also tried to investigate possible relationships between reinterventions and some clinical or angiographical conditions. We considered particular characteristics significant from procedures' point of view like size of implanted stent, number of patent arteries below the knee or dual antiplatelet therapy use.

\section{Material and methods}

Over a period of three years (from 2012 to 20I5) among all patients with symptomatic peripheral arterial disease hospitalized in the Department of Vascular Surgery and Angiology Medical University of Lublin, 


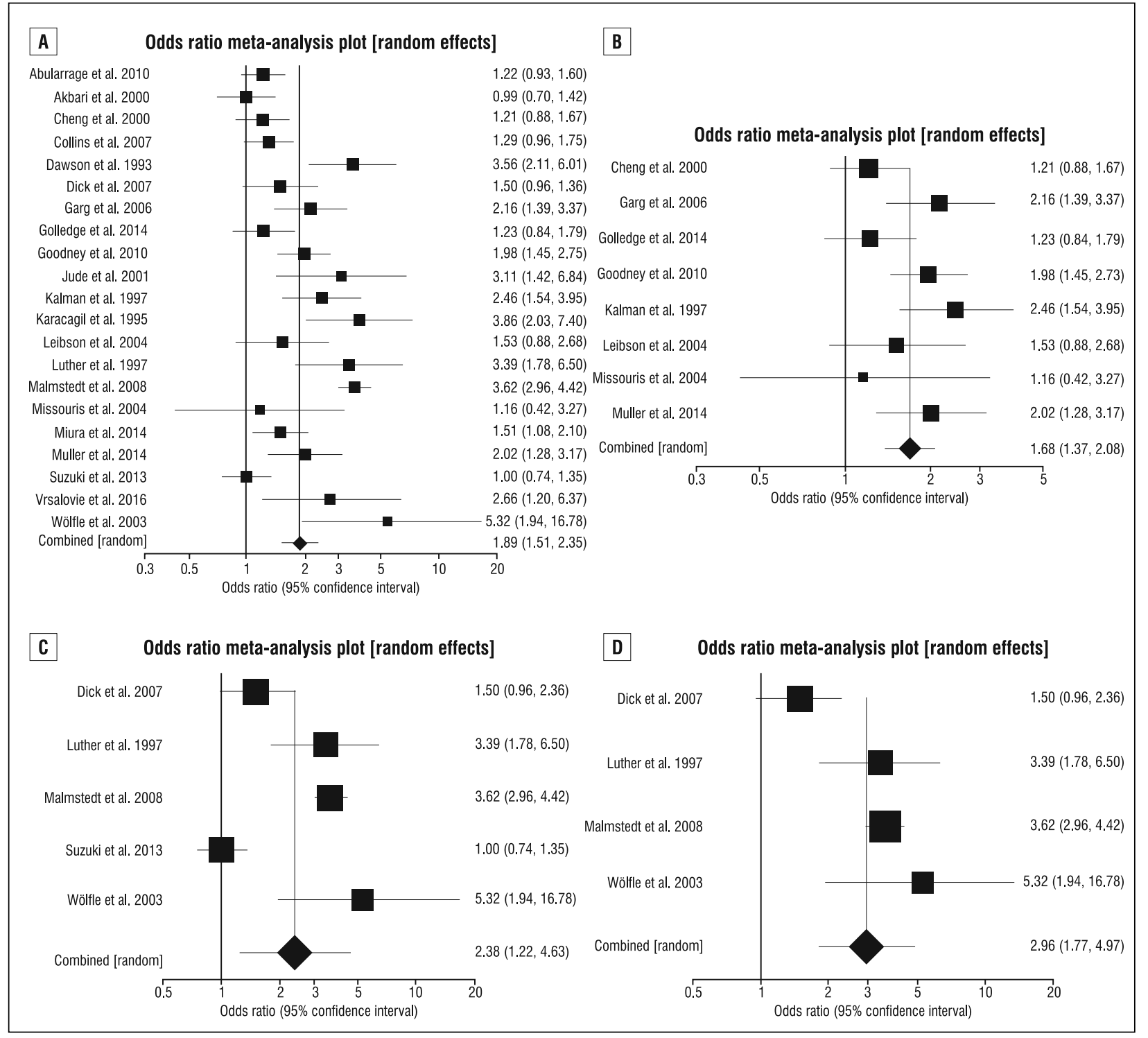

Figure I. Meta-analysis (random effects model) testing the association between diabetes and all-cause mortality in (A) all studies with peripheral artery disease, (B) prospective studies with performed multivariate analysis without critical limb ischemia, (C) all studies with critical limb ischemia, and (D) Caucasian studies with critical limb ischemia. Data from literature [3]

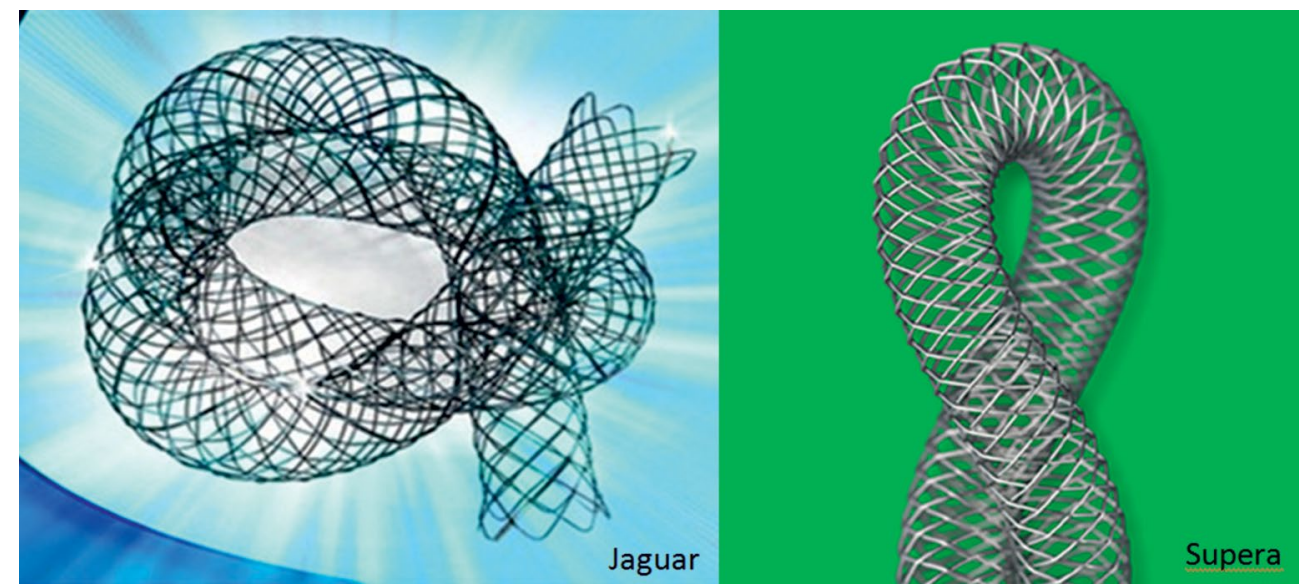

Figure 2. Jaguar and Supera nitinol self-expanding stents 
who underwent percutaneous transluminal angioplasty (PTA) and stenting we chose all treated with two kinds of self-expanding nitinol stents: Jaguar (Balton) and Supera (Abbott). The study group consisted of 60 patients - 47 males and I 3 females aged from 46 to 85 (average 66.77) and were subdivided into stages of Fontaine classification. The group was composed of both elective and also more urgent patients with critical limb ischemia. The retrospective analysis based on medical records was performed. Diagnosis of peripheral arterial disease was based on typical anamnesis and ultrasound examination with Doppler. Indication for endovascular treatment and final qualification was confirmed directly after arteriography. All interventions were performed under local anesthesia with use of $5-10 \mathrm{~mL} 2 \%$ lidocaine solution, in most cases through femoral access, using $6 \mathrm{~F}$ introducers. After arteriography and balloon angioplasty in all patients nitinol stent Jaguar or Supera was implanted. There were no complications and no need to surgical conversion.

Whole study group was monitored for the presence of cardiovascular risk factors and also for potential restenosis risk factors as diabetes mellitus, chronic kidney disease and diameter or length of implanted stents. Retrospectively we detected all patients with reintervention in treated artery and examined potential relevance to risk factors and some angiographical findings. We compared two subgroups: patients who experienced and did not experience reintervention.

\section{Results}

In 36 patients (60\%) symptoms of Fontaine Ilb stage were present. Critical limb ischemia (CLI) defined as the presence of ischemic rest pain (Fontaine stage III) or ulcers or gangrene (Fontaine stage IV) was present respectively in $14(23 \%)$ and 9 (15\%) patients, while only one patient ( $1.67 \%)$ was in Fontaine stage Ila.

In angiography patency of all three vessels below the knee was observed in 26 patients (43\%), two patent arteries in next $16(26.7 \%)$ and one vessel also in 16 patients $(26.7 \%)$. Lack of any patent artery was noted in one patient (3.3\%). Dual antiplatelet therapy at discharge received 54 patients (90\%), whereas one antiplatelet drug was prescribed to another 6 patients (10\%).

After arteriography and balloon angioplasty in 33 patients $(55 \%)$ nitinol stent Jaguar and in 27 patients (45\%) Supera were implanted. Both of these subgroups did not show any significant differences in demographics, as well as cardiovascular risk factors burden. Subgroups were also similar in regard to dual antiplatelet therapy $(p=0.56)$ and number of patent peripheral arteries $(p=0.55)$.

Repeat target lesion revascularization was performed in 14 patients (42\%) who received Jaguar and in $10(37 \%)$ who received Supera stents. Therefore, none of these stents turned to be related to higher or lower reintervention rate $(p=0.43)$. Sizes of implanted stents are shown in Figure 3 and 4.

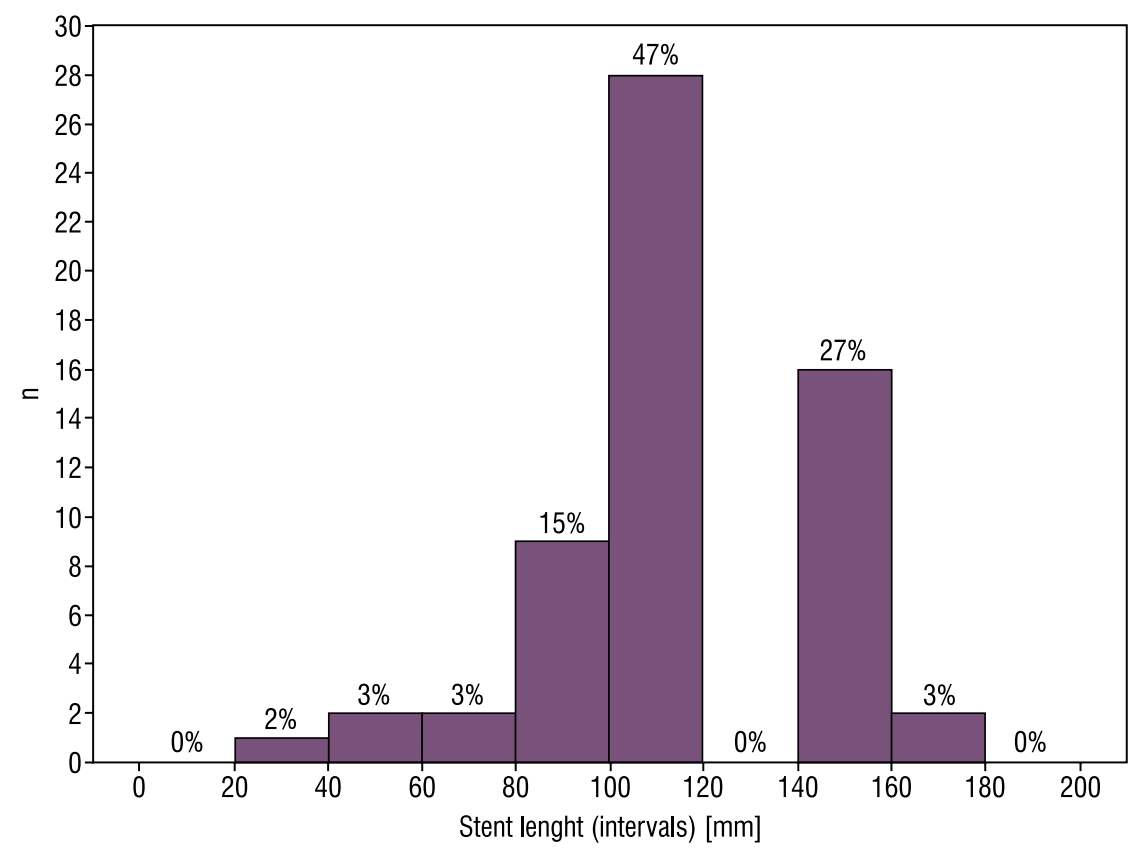

Figure 3. Length of stents used in study group 


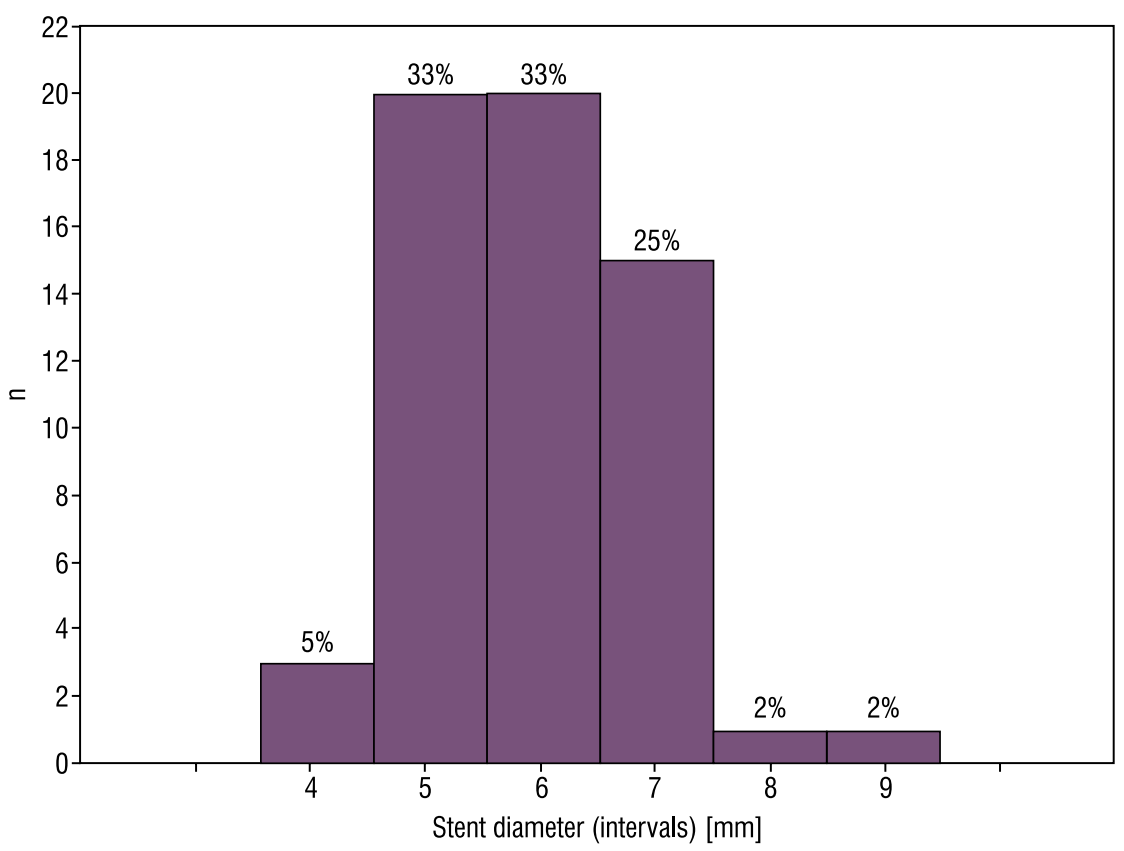

Figure 4. Diameter of stents used in study group

Table 2. Comparison of groups with and without reinterventions - risk factors

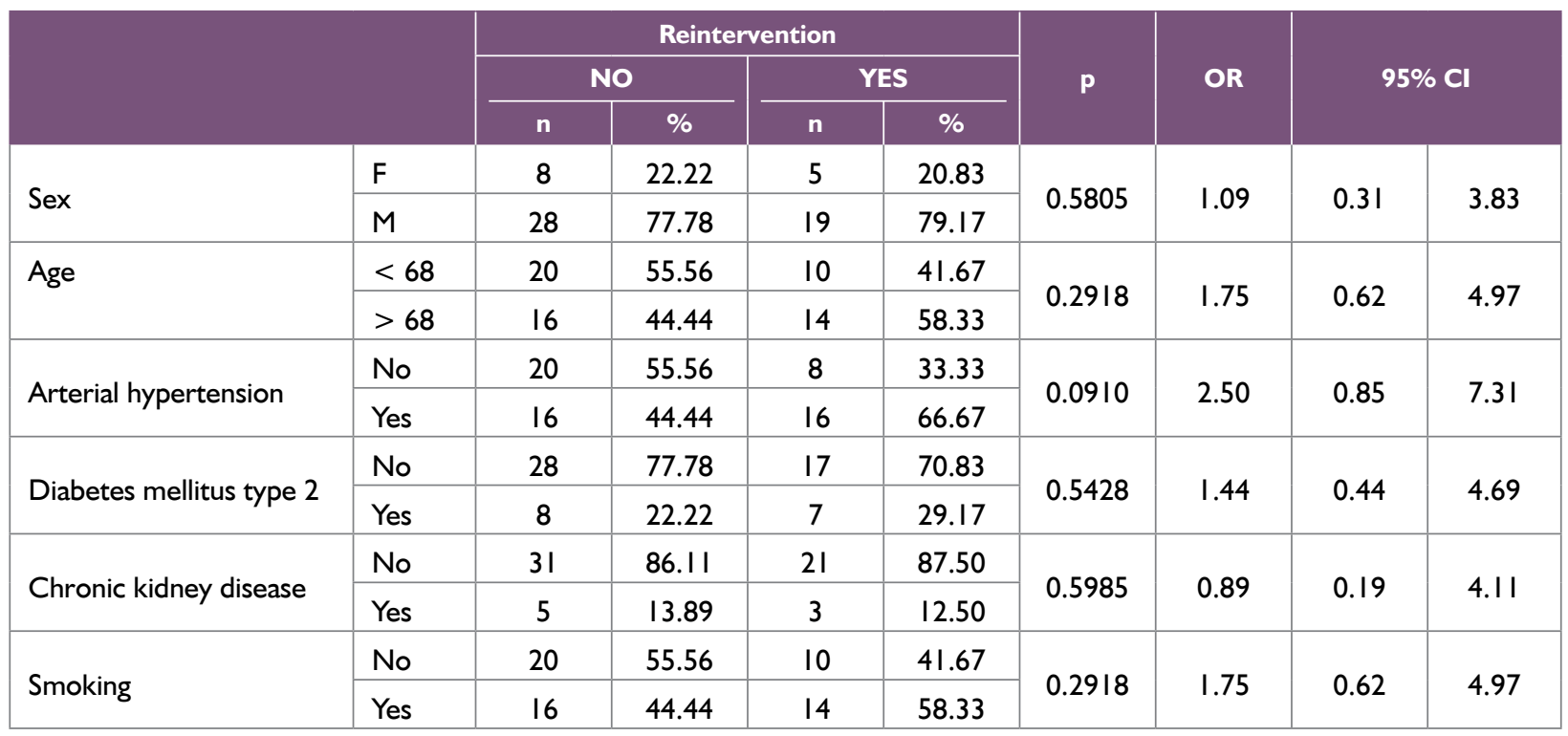

In the analysis whole study group was divided into 2 subgroups - 24 patients (40\%) who underwent reintervention and $36(60 \%)$ without need of repeated target lesion revascularization. Mean time to reintervention was 5.91 months ( \pm 4.43 months), whereas follow-up ranged from I to 42 months (mean 24.5 months).

Incidence of peripheral arterial disease risk factors in subgroups of patients with or without reintervention, as well as some procedural and periprocedural data for both groups were collected and analyzed (Table 2 and 3 ).

Among cardiovascular risk factors hyperlipidemia, type 2 of diabetes mellitus and chronic kidney disease were not associated with reintervention, whereas arterial hypertension was associated with a higher risk of target lesion revascularization ( $O R=2.5)$. Reintervention occurred more often also in patients older than $68(\mathrm{OR}=\mathrm{I} .75)$, and smokers $(\mathrm{OR}=\mathrm{I} .75)$. 
Table 3. Comparison of groups with and without reinterventions - procedural and periprocedural data

\begin{tabular}{|c|c|c|c|c|c|c|c|c|c|}
\hline & & \multicolumn{4}{|c|}{ Reintervention } & \multirow{3}{*}{$\mathbf{p}$} & \multirow{3}{*}{ OR } & \multirow{2}{*}{\multicolumn{2}{|c|}{$95 \% \mathrm{Cl}$}} \\
\hline & & \multicolumn{2}{|c|}{ No } & \multicolumn{2}{|c|}{ YES } & & & & \\
\hline & & n & $\%$ & $\mathbf{n}$ & $\%$ & & & & \\
\hline \multirow{2}{*}{ Stent } & Jaguar & 19 & 52.78 & 14 & 58.33 & \multirow{2}{*}{0.6717} & \multirow{2}{*}{0.80} & \multirow{2}{*}{0.28} & \multirow{2}{*}{2.2} \\
\hline & Supera & 17 & 47.22 & 10 & 41.67 & & & & \\
\hline \multirow{2}{*}{ Lenght } & $<120$ & 14 & 38.89 & 10 & 41.67 & \multirow{2}{*}{0.8296} & \multirow{2}{*}{0.89} & \multirow{2}{*}{0.31} & \multirow{2}{*}{2.55} \\
\hline & $>120$ & 22 & 61.11 & 14 & 58.33 & & & & \\
\hline \multirow{2}{*}{ Diameter } & $<6$ & 15 & 41.67 & 8 & 33.33 & \multirow{2}{*}{0.5154} & \multirow{2}{*}{1.43} & \multirow{2}{*}{0.49} & \multirow{2}{*}{4.19} \\
\hline & $>6$ & 21 & 58.33 & 16 & 66.67 & & & & \\
\hline \multirow{2}{*}{ Antiplatelet drugs } & I & 3 & 8.33 & 3 & 12.50 & \multirow{2}{*}{0.4556} & \multirow{2}{*}{0.64} & \multirow{2}{*}{0.12} & \multirow{2}{*}{3.45} \\
\hline & 2 & 33 & 91.67 & 21 & 87.50 & & & & \\
\hline
\end{tabular}

Table 4. Comparison of groups with and without reinterventions

\begin{tabular}{|c|c|c|c|c|c|c|}
\hline & & \multicolumn{4}{|c|}{ Reintervention } & \multirow{3}{*}{$\mathbf{P}$} \\
\hline & & \multicolumn{2}{|c|}{ No } & \multicolumn{2}{|c|}{ YES } & \\
\hline & & $\mathbf{n}$ & $\%$ & n & $\%$ & \\
\hline \multirow{4}{*}{ Fontaine stage } & Ila & 1 & 2.78 & 0 & 0.00 & \multirow{4}{*}{0.8279} \\
\hline & Ilb & 21 & 58.33 & 15 & 62.50 & \\
\hline & III & 9 & 25.00 & 5 & 20.83 & \\
\hline & IV & 5 & 13.89 & 4 & 16.67 & \\
\hline \multirow{4}{*}{ Patent arteries below the knee } & 0 & 1 & 2.78 & 1 & 4.17 & \multirow{4}{*}{$<0.05$} \\
\hline & $\mathrm{I}$ & 11 & 30.56 & 5 & 20.83 & \\
\hline & 2 & 5 & 13.89 & II & 45.83 & \\
\hline & 3 & 19 & 52.78 & 7 & 29.17 & \\
\hline
\end{tabular}

Interestingly, need of reintervention in our group was not correlated with a diameter or length of implanted stents. Fontaine stage also did not determine intervention rate, while patency of all three arteries below the knee was associated with a significantly lower reintervention risk (Table 4).

Additionally, in Cox regression model no independent variables were shown, which were responsible for need of reintervention $\left(\chi^{2}=13.96 ; p=0.2355\right)$ (Table 5).

\section{Discussion}

Since peripheral arterial disease may be asymptomatic for months and years, it is often diagnosed in advanced stage with observed diffuse, occlusive and multifocal lesions, which results in worse endovascular treatment outcomes, when compared to less advanced forms (TASC A-B). Patients with iliac and femoral lesions represent substantial proportion of patients with signs of peripheral arterial disease, because such localization determines more severe symptoms and enables early diagnosis. This was also confirmed in our study group, which included really symptomatic patients - only one of them was in Fontaine stage Ila.

Endovascular procedures are widely accepted methods of treating patients with iliac and femoral TASC A-B lesions [4]. Recent data show, that many of more complex lesions (TASC C-D) can be safely treated with primary self-expanding nitinol stents with acceptable long-term primary patency rates [16]. On the other hand many studies including one with group of 2096 patients and $260 \mathrm{I}$ treated limbs reported lower technical success and higher complications rate of aorto-iliac interventions in TASC D lesions in comparison to TASC A-C lesions [17].

As mentioned above evidence on superiority of primary self-expanding nitinol stents implantation strategy over methods based on balloon angioplasty with optional secondary stenting is uncertain. However, there are more and more papers providing this assumption and primary use of those devices seems to be dominant endovascular way of treatment in the nearest future. Dick et al showed a lower restenosis rate after self-expanding 
Table 5. Cox regression model data

\begin{tabular}{|l|c|c|c|c|c|c|} 
& Beta & $\begin{array}{c}\text { Standard } \\
\text { error }\end{array}$ & t-value & $\begin{array}{c}\text { Exponent } \\
\text { beta }\end{array}$ & Wald statist. & p \\
\hline Sex & -0.41 & 0.66 & -0.61 & 0.67 & 0.38 & 0.5402 \\
\hline Stent lenght & 0.01 & 0.01 & 0.88 & 1.01 & 0.78 & 0.3772 \\
\hline Stent diameter & 0.51 & 0.37 & 1.37 & 1.66 & 1.89 & 0.1693 \\
\hline Fontaine class & -0.48 & 0.27 & -1.77 & 0.62 & 3.14 & 0.0766 \\
\hline Age & -0.05 & 0.04 & -1.35 & 0.95 & 1.81 & 0.1781 \\
\hline Arterial hypertension & -1.16 & 0.62 & -1.87 & 0.31 & 3.50 & 0.0613 \\
\hline Diabetes mellitus type 2 & -0.84 & 0.68 & -1.24 & 0.43 & 1.55 & 0.2137 \\
\hline Smoking & -0.59 & 0.60 & -1.00 & 0.55 & 0.99 & 0.3195 \\
\hline Chronic kidney disease & 0.19 & 0.77 & 0.25 & 1.21 & 0.06 & 0.7996 \\
\hline Patent arteries below the knee & -0.37 & 0.35 & -1.07 & 0.69 & 1.13 & 0.2868 \\
\hline Antiplatelet therapy & -1.41 & 0.87 & -1.62 & 0.24 & 2.62 & 0.1055 \\
\hline
\end{tabular}

nitinol stent implantation in SFA lesion over PTA after 6 months, and further benefits were observed after one year [13]. Similar results were reported by Schillinger et al. [14]. Iliac lesions treatment were also a subject of numerous trials and some meta-analyses, which showed a prevalence of primary stenting over PTA alone, in both hemodynamic parameters and clinical symptoms classifications [18-20]. The benefits were also shown in self-expanding stents studies [2I, 22].

A placement of stents is accepted therapy for iliac and femoral artery occlusive disease. Selective provisional stenting to salvage iliac lesions after failed or unsatisfactory PTA due to elastic recoil, flow-limiting dissection or residual gradient, is well established. A primary stent implantation strategy offers additional benefits, including improved technical success and ability to treat complex disease. Moreover, such complications like flow-limiting dissection and acute artery closure are significantly decreased, and long-term restenosis rates appear to be significantly improved.

A further trials are necessary to establish role of novel devices like drug eluting stents in achieving durable results and confirm present short-term observations $[23,24]$. Some promising techniques for instance common femoral artery angioplasty with optional bifurcation treatment requires validation and appear to be interesting option and alternative to surgery way of treatment [25].

In our study group a very high success rate of the procedures reflects and confirms the advantages of implanted stents - 100\% procedures was finished with stent implantation and none of patients required urgent surgical intervention as a result of complication.

However, we observed high risk of reintervention rate in our study group ( $40 \%$ ) despite the fact, that follow-up was based on symptoms, not on elective arteriography as an element of study. This means, that the restenosis rate might even be higher than $40 \%$, if all patients would undergo arteriography. Some authors also report high restenosis and reintervention rate. Yu et. al demonstrated disappointing results of SFA stenting with bare metal stents with the primary and secondary patency rates at two years respectively $22 \%$ and $58 \%$ [26]. Factors correlated with reinterventions in this study were: diabetes mellitus [HR (hazard ratio) $=2.50$; $p=0.039]$, long lesions $>8 \mathrm{~cm}(H R=2.62 ; p=0.04)$ and TASC C-D lesions $(H R=2.05 ; p=0.03)$, but chronic kidney disease showed trend toward higher intervention rate $(H R=1.72)$.

We noticed a large risk factors burden in our study group - in particular over $98 \%$ of patients had a lipid disorders history and $100 \%$ patients were treated with statin and aspirin. We examined influence of various factors and did not confirm the correlation between diabetes mellitus and higher reintervention rate, reported in other previous studies [26, 27]. We did not observe also relation of chronic kidney disease to reinterventions, which was comparable to other studies [27]. On the other hand, surprising was the observation, that neither diameter nor length of implanted stents affected reintervention rate. What is interesting, arterial hypertension turned to be associated with higher risk of reintervention $(O R=2.5)$ and smoking or age older than 68 demonstrated a trend toward higher risk of repeated target lesion revascularization $(\mathrm{OR}=\mathrm{I} .75)$.

Finally, as we expected, general rule that adequate inflow and appropriate outflow are required to keep revascularized segment functioning was also confirmed in our study. Presence of all three patent vessel below 
the knee was significant factor preventing from re-intervention $(p<0.05)$.

\section{Conclusions}

I. There was no difference between both stents in terms of target lesion revascularization rate.

2. Arterial hypertension was associated with higher risk of reintervention and smoking or older age demonstrated a trend toward higher risk of repeated target lesion revascularization.

3. Three patent arteries below the knee was associated with lower re-intervention rate, but we did not observed the size of the stents impact on reintervention rate.

\section{References}

I. Fowkes FG, Rudan D, Rudan I, et al. Comparison of global estimates of prevalence and risk factors for peripheral artery disease in 2000 and 2010: a systematic review and analysis. Lancet. 2013; 382(9901): 1329-1340, doi: 10.1016/S01406736(13)6/249-0, indexed in Pubmed: 23915883.

2. Muller MD, Reed AB, Leuenberger UA, et al. Physiology in medicine: peripheral arterial disease. J Appl Physiol (1985). 2013; II5(9): 1219-1226, doi: 10.1 152/japplphysiol.00885.2013, indexed in Pubmed: 23970534.

3. Vrsalovic M, Vucur K, Vrsalovic Presecki A, et al. Impact of diabetes on mortality in peripheral artery disease: a meta-analysis. Clin Cardiol. 2017; 40(5): 287-29I, doi: 10.1002/clc.22657, indexed in Pubmed: 28026025.

4. Norgren L, Hiatt WR, Dormandy JA, et al. Inter-Society Consensus for the Management of Peripheral Arterial Disease (TASC II). Eur J Vasc Endovasc Surg. 2007; 33(1): SI-S75, doi: 10.1016/j. ejvs.2006.09.024.

5. Gerhard-Herman MD, Gornik HL, Barrett C, et al. 2016 AHA/ IACC Guideline on the Management of Patients With Lower Extremity Peripheral Artery Disease: Executive Summary: A Report of the American College of Cardiology/American Heart Association Task Force on Clinical Practice Guidelines. Circulation. 2017; 135(I2): e686-e725, doi: 10.1161/ CIR.0000000000000470, indexed in Pubmed: 27840332.

6. Tendera M, Aboyans V, Bartelink ML, et al. European Stroke Organisation, ESC Committee for Practice Guidelines. ESC Guidelines on the diagnosis and treatment of peripheral artery diseases: Document covering atherosclerotic disease of extracranial carotid and vertebral, mesenteric, renal, upper and lower extremity arteries: the Task Force on the Diagnosis and Treatment of Peripheral Artery Diseases of the European Society of Cardiology (ESC). Eur Heart J. 20I I; 32(22): 285I-2906, doi: 10.1093/eurheartj/ehr2II, indexed in Pubmed: 218734I7.

7. Jones WS, Patel MR, Dai D, et al. High mortality risks after major lower extremity amputation in Medicare patients with peripheral artery disease. Am Heart J. 2013; 165(5): 809-815, doi: 10.1016/j.ahj.2012.12.002, indexed in Pubmed: 23622919.

8. Martini R, Andreozzi GM, Deri A, et al. Amputation rate and mortality in elderly patients with critical limb ischemia not suita- ble for revascularization. Aging Clin Exp Res. 2012; 24(3 suppl): 24-27.

9. Swaminathan A, Vemulapalli S, Patel MR, et al. Lower extremity amputation in peripheral artery disease: improving patient outcomes. Vasc Health Risk Manag. 2014; 10: 417-424, doi: 10.2147/NHRM.S50588, indexed in Pubmed: 250751 92.

10. Krankenberg H, Schlüter M, Steinkamp HJ, et al. Nitinol stent implantation versus percutaneous transluminal angioplasty in superficial femoral artery lesions up to $10 \mathrm{~cm}$ in length: the femoral artery stenting trial (FAST). Circulation. 2007; I I6(3): 285-292, doi: 10.1 16I/CIRCULATIONAHA. 107.689141, indexed in Pubmed: 17592075.

II. Chalmers N, Walker PT, Belli AM, et al. Randomized trial of the SMART stent versus balloon angioplasty in long superficial femoral artery lesions: the SUPER study. Cardiovasc Intervent Radiol. 2013; 36(2): 353-36I, doi: 10.1007/s00270-0I2-0492-z, indexed in Pubmed: 23070104.

12. Laird JR, Katzen BT, Scheinert D, et al. RESILIENT Investigators. Nitinol stent implantation vs. balloon angioplasty for lesions in the superficial femoral and proximal popliteal arteries of patients with claudication: three-year follow-up from the RESILIENT randomized trial. J Endovasc Ther. 2012; 19(I): 1-9, doi: 10.1583/I I-3627. I, indexed in Pubmed: 22313193.

13. Dick P, Wallner H, Sabeti S, et al. Balloon angioplasty versus stenting with nitinol stents in intermediate length superficial femoral artery lesions. Catheter Cardiovasc Interv. 2009; 74(7): 1090-1095, doi: 10.1002/ccd.22128, indexed in Pubmed: 19859954.

14. Dick P, Wallner H, Sabeti S, et al. Balloon angioplasty versus implantation of nitinol stents in the superficial femoral artery. N Engl J Med. 2006; 354(18): 1879-1888, doi: 10.1056/NEJMoa051303, indexed in Pubmed: 16672699.

15. Kordecki K, Lukasiewicz A, Nowicki M, et al. Assessment of effectiveness of endovascular treatment of common and external iliac artery stenosis/occlusion using self-expanding Jaguar SM stents. Pol J Radiol. 2012; 77(4): 22-29, indexed in Pubmed: 23269933.

16. Elmahdy MF, Buonamici P, Trapani M, et al. Long-Term Primary Patency Rate After Nitinol Self-Expandable Stents Implantation in Long, Totally Occluded Femoropopliteal (TASC II C \& D) Lesions. Heart Lung Circ. 2017; 26(6): 604-6II, doi: 10.1016/j. hlc.2016.09.01 I, indexed in Pubmed: 27939742.

17. Suzuki K, Mizutani Y, Soga Y, et al. Efficacy and Safety of Endovascular Therapy for Aortoiliac TASC D Lesions. Angiology. 2017; 68(I): 67-73, doi: 10.1177/0003319716638005, indexed in Pubmed: 26980775.

18. Bosch JL, Hunink MG. Meta-analysis of the results of percutaneous transluminal angioplasty and stent placement for aortoiliac occlusive disease. Radiology. 1997; 204(I): 87-96, doi: 10.1 I48/ radiology.204.1.9205227, indexed in Pubmed: 9205227.

19. Treiman G, Schneider P, Lawrence P, et al. Does stent placement improve the results of ineffective or complicated iliac artery angioplasty? J Vasc Surg. 1998; 28(I): 104-I14, doi: 10.1016/ s074I-52 I 4(98)70205-8.

20. Powell RJ, Fillinger M, Walsh DB, et al. Predicting outcome of angioplasty and selective stenting of multisegment iliac artery occlusive disease. J Vasc Surg. 2000; 32(3): 564-569, doi: 10.1067/mva.2000.107760, indexed in Pubmed: 10957665. 
21. Krol KL, Saxon RR, Farhat N, et al. Clinical evaluation of the Zilver vascular stent for symptomatic iliac artery disease. J Vasc Interv Radiol. 2008; 19(1): 15-22, doi: 10.1016/j.jvir.2007.08.031, indexed in Pubmed: 18192463.

22. Jaff MR, Katzen BT. Two-year clinical evaluation of the Zilver vascular stent for symptomatic iliac artery disease. J Vasc Interv Radiol. 2010; 21 (10): 1489-1494, doi: 10.1016/j.jvir.2010.06.013, indexed in Pubmed: 20801673.

23. Duda SH, Pusich B, Richter G, et al. Sirolimus-eluting stents for the treatment of obstructive superficial femoral artery disease: six-month results. Circulation. 2002; 106(12): 1505-1509, indexed in Pubmed: 12234956.

24. Dake MD, Ansel GM, Jaff MR, et al. Zilver PTX Investigators. Paclitaxel-eluting stents show superiority to balloon angioplasty and bare metal stents in femoropopliteal disease: twelve-month Zilver PTX randomized study results. Circ Cardiovasc
Interv. 20II; 4(5): 495-504, doi: 10.1 I6I/CIRCINTERVENTIONS. III.962324, indexed in Pubmed: 21953370.

25. Bonvini RF, Rastan A, Sixt S, et al. Endovascular treatment of common femoral artery disease: medium-term outcomes of 360 consecutive procedures. J Am Coll Cardiol. 20II; 58(8): 792-798, doi: 10.1016/j.jacc.2011.01.070, indexed in Pubmed: 21835313.

26. Yu JS, Park KM, Jeon YS, et al. Midterm outcome of femoral artery stenting and factors affecting patency. Vasc Specialist Int. 20I5; 3I (4): II5-II9, doi: 10.5758/vsi.20I5.3I.4.II5, indexed in Pubmed: 267। 9837.

27. Bakken AM, Protack CD, Saad WE, et al. Impact of chronic kidney disease on outcomes of superficial femoral artery endoluminal interventions. Ann Vasc Surg. 2009; 23(5): 560 -568 , doi: 10.1016/j.avsg.2008.11.010, indexed in Pubmed: 19128934 . 